\title{
Stereotactic radiosurgery for WHO grade I posterior fossa meningiomas: long-term outcomes with volumetric evaluation
}

\author{
Mohana Rao Patibandla, MCh, ${ }^{1}$ Cheng-chia Lee, MD, ${ }^{2}$ Athreya Tata, BA, ${ }^{1}$ \\ Gokul Chowdary Addagada, MBBS, ${ }^{3}$ and Jason P. Sheehan, MD, PhD ${ }^{1}$
}

1Department of Neurological Surgery, University of Virginia, Charlottesville, Virginia; ${ }^{2}$ Department of Neurosurgery, Neurological Institute, Taipei Veteran General Hospital, Taipei, Taiwan; and ${ }^{3}$ Guntur Medical College, Guntur, Andhra Pradesh, India

OBJECTIVE Research over the past 2 decades has been characterizing the role of stereotactic radiosurgery (SRS) in the treatment of benign intracranial tumors, including meningiomas. However, few studies have examined the long-term outcomes of SRS treatment for posterior fossa meningiomas (PFMs). Furthermore, previous studies have typically used single diameter measurements when reporting outcomes, which can yield misleading results. The authors describe the use of SRS in the treatment of benign WHO grade I PFMs and correlate volumetric analysis with long-term outcomes.

METHODS This study is a retrospective analysis of a prospectively maintained IRB-approved database. Inclusion criteria were a diagnosis of WHO grade I PFM with subsequent treatment via single-session SRS and a minimum of 3 followup MRI studies available. Volumetric analysis was performed on the radiosurgical scan and each subsequently available follow-up scan by using slice-by-slice area calculations of the meningioma and numerical integration with the trapezoid rule.

RESULTS The final cohort consisted of 120 patients, $76.6 \%$ (92) of whom were female, with a median age of 61 years (12-88 years). Stereotactic radiosurgery was the primary treatment for $65 \%$ (78) of the patients, whereas $28.3 \%$ (34) had 1 resection before SRS treatment and $6.7 \%$ (8) had 2 or more resections before SRS. One patient had prior radiotherapy. Tumor characteristics included a median volume of $4.0 \mathrm{~cm}^{3}\left(0.4-40.9 \mathrm{~cm}^{3}\right)$ at treatment with a median margin dose of $15 \mathrm{~Gy}$ (8-20 Gy). The median clinical and imaging follow-ups were 79.5 (15-224) and 72 (6-213) months, respectively. For patients treated with a margin dose $\geq 16 \mathrm{~Gy}$, actuarial progression-free survival rates during the period 2-10 years post-SRS were $100 \%$. In patients treated with a margin dose of 13-15 Gy, the actuarial progression-free survival rates at $2,4,6,8$, and 10 years were $97.5 \%, 97.5 \%, 93.4 \%, 93.4 \%$, and $93.4 \%$, respectively. Those who were treated with $\leq 12 \mathrm{~Gy}$ had actuarial progression-free survival rates of $95.8 \%, 82.9 \%, 73.2 \%, 56.9 \%$, and $56.9 \%$ at $2,4,6,8$, and 10 years, respectively. The overall tumor control rate was $89.2 \%$ (107 patients). Post-SRS improvement in neurological symptoms occurred in $23.3 \%$ (28 patients), whereas symptoms were stable in $70.8 \%$ ( 85 patients) and worsened in $5.8 \%$ (7 patients). Volumetric analysis demonstrated that a change in tumor volume at 3 years after SRS reliably predicted a volumetric change and tumor control at 5 years $\left(R^{2}=0.756\right)$ with a $p<0.001$ and at 10 years $\left(R^{2}=0.421\right)$ with a $p=$ 0.001 . The authors also noted that the 1 - to 5 -year tumor response is predictive of the 5 - to 10 -year tumor response $\left(R^{2}\right.$ $=0.636, p<0.001$.

CONCLUSIONS Stereotactic radiosurgery, as an either upfront or adjuvant treatment, is a durable therapeutic option for WHO grade I PFMs, with high tumor control and a low incidence of post-SRS neurological deficits compared with those obtained using alternate treatment modalities. Lesion volumetric response at the short-term follow-up of 3 years is predictive of the long-term response at 5 and 10 years.

https://thejns.org/doi/abs/10.3171/2017.6.JNS17993

KEY WORDS meningioma; stereotactic radiosurgery; Gamma Knife; posterior fossa; cerebellopontine angle; petroclival; foramen magnum; tentorial; SRS

ABBREVIATIONS GKRS = Gamma Knife radiosurgery; PFM = posterior fossa meningioma; PFS = progression-free survival; SRS = stereotactic radiosurgery.

SUBMITTED April 19, 2017. ACCEPTED June 30, 2017.

INCLUDE WHEN CITING Published online January 5, 2018; DOI: 10.3171/2017.6.JNS17993. 
$\mathrm{M}$ ENINGIOMAS account for nearly a third of all primary intracranial tumors, making them one of the most common types of intracranial tumors. 22,68 Posterior fossa meningiomas (PFMs) comprise about $7 \%-12 \%$ of intracranial meningiomas. ${ }^{18,69}$ Surgical treatment of skull base meningiomas has significantly improved through advances in microsurgical techniques, diagnostic and interventional radiology, anesthesia and postoperative management, and interdisciplinary care. ${ }^{60}$ Thus, complete resection whenever possible remains preferable for many symptomatic or progressive lesions. ${ }^{62}$ However, a drawback of resection even via microsurgical techniques is the neurological impairment frequently associated with the surgical treatment of these challenging skull base lesions, and meningioma recurrence has been described even after complete resection. 1,2,4-10,12,14,18,24,27-29,32,35,39,51,54,55,57-59,64

Stereotactic radiosurgery (SRS) is increasingly used for both primary and adjuvant treatment of meningiomas. While this procedure has become widely applied in the treatment of skull base lesions, there have been few large studies describing its use for PFMs and even fewer with

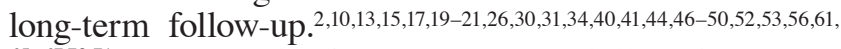
65-67,70,71 The posterior fossa has an especially unique anatomy with little room for mass effect, which in turn creates particular surgical and radiosurgical constraints.

The unique architecture of the posterior fossa also results in complex potential growth patterns. Single-dimension diameter measurements for lesions in this location can thus yield misleading information. While many recommend volumetric measurement for follow-up, the technical constraints have as yet precluded its widespread use. ${ }^{16,25,33,63}$ In the current study, we describe the treatment of benign WHO grade I PFMs with single-session SRS as well as the long-term outcomes correlated with timing and volumetric changes in these lesions.

\section{Methods \\ Patient Population}

This study is a retrospective analysis of a prospectively maintained database with approval from the IRB at the University of Virginia. The database was searched for patients with a benign meningioma involving the posterior fossa region that had been treated with single-session SRS between 1991 and 2014. Inclusion criteria were clinical and radiological features consistent with a benign WHO grade I meningioma located in the posterior fossa of the skull base and a minimum of 3 available follow-up MRI scans post-SRS. Patients who had undergone SRS as a primary treatment lacked a definitive histological diagnosis. Radiological features consistent with benign meningioma included an extraaxial location, attachment to the dura (a dural tail), uniform contrast enhancement, and/or intratumoral calcification. Patients were excluded if they had a history of cancer, CT imaging alone, a WHO grade II or III meningioma, or multiple meningiomas suggestive of neurofibromatosis type 2 or other tumor-related genetic predispositions.

\section{Radiosurgical Technique \\ Details of the Gamma Knife radiosurgery (GKRS)}

technique employed at the University of Virginia have been described in a prior study. ${ }^{65}$ In brief, the Leksell Gamma Knife model U was used until July 2001. Subsequently, the model $\mathrm{C}$ was instituted and used until September 2007. Since then, the Gamma Knife Perfexion model has been used. For dose planning, Kula software was used until June 1994, and GammaPlan software was used thereafter (both Elekta Instruments, AB). Dose plans and other radiosurgical parameters were formulated under the direction of the treating neurosurgeon in conjunction with a medical physicist and radiation oncologist. ${ }^{61}$ Highresolution stereotactic MRI was performed after stereotactic frame placement. Thin-slice axial and/or coronal plane images were obtained after intravenous contrast administration. The details of stereotactic imaging for radiosurgical planning varied over time, but planning generally included pre- and postcontrast, volumetrically acquired gradient-echo pulse sequences reconstructed into axial and coronal image stacks. Voxel sizes varied from $(1 \times 1 \times$ $3 \mathrm{~mm})$ to $(1 \times 1 \times 1.3 \mathrm{~mm})$.

The median dose to the tumor margin was $15 \mathrm{~Gy}$ (range 8-20 Gy) along a mean isodose of 50\% (range 30\%-60\%; Table 1). A multi-isocentric approach was predominantly used with a mean of 10 isocenters (range 1-52 isocenters). An empirical algorithm was used for dose selection. Factors that influenced dose selection include tumor volume, lesion proximity to the brainstem and other critical neurovascular structures, any history of prior fractionated radiation therapy, and any previously existing neurological deficits.

\section{Clinical and Radiological Follow-Up}

After treatment with SRS, clinical evaluations with accompanying radiological scanning were performed approximately every 6 months for the first 2 years. Thereafter, if the patient showed no evidence of tumor growth on scans and did not experience deterioration or develop new neurological findings, follow-up intervals were increased to every 1-2 years. An attending neurosurgeon and neuroradiologist at the University of Virginia reviewed each neuroimaging study. The response of tumors, based on volumetric analysis, was considered to be stable if it was within $10 \%$ of the tumor volume at the time of treatment (original volume), increased if it was greater than $10 \%$ of the original volume, and decreased if it was at least $10 \%$ smaller than its original volume. ${ }^{17,63}$ Adverse radiation effects were defined as new or worsening perilesional hyperintensity noted on T2-weighted or FLAIR MRI sequences in the post-SRS follow-up. Radionecrosis was defined on the basis of neuroimaging studies (for example, PET, SPECT, and MR perfusion) or biopsy results that would be consistent with necrosis.

\section{Tumor Volumetric Assessment}

The Gamma Knife planning software (GammaPlan) for the initial volumetric assessment on the planning stereotactic MR image or the NIH ImageJ software for all follow-up MR images was used for volume determinations, as previously described..$^{25,63}$ Volumetric calculations for PFMs were performed longitudinally for each patient 
TABLE 1. Summary characteristics for 120 patients with PFMs treated using GKRS

\begin{tabular}{|c|c|}
\hline Characteristic & Value \\
\hline $\operatorname{Sex}(M / F)$ & $28 / 92$ \\
\hline Median age in yrs (range) & $61(12-88)$ \\
\hline Median pre-SRS tumor vol in $\mathrm{cm}^{3}$ (range) & $4.0(0.4-40.9)$ \\
\hline \multicolumn{2}{|l|}{ No. of tumors (no. [\%]) } \\
\hline 1 & $111(92.5)$ \\
\hline 2 & $8(6.7)$ \\
\hline 3 & $1(0.8)$ \\
\hline \multicolumn{2}{|l|}{ Tumor location (no. [\%]) } \\
\hline Tentorium & $28(23.3)$ \\
\hline CPA & $38(31.7)$ \\
\hline Petroclival region & $23(19.2)$ \\
\hline Petrous region & $2(1.7)$ \\
\hline Foramen magnum & $4(3.3)$ \\
\hline Clivus & $24(20.0)$ \\
\hline Tentorium \& CPA & $1(0.8)$ \\
\hline \multicolumn{2}{|l|}{ Previous resection (no. [\%]) } \\
\hline 0 & $78(65)$ \\
\hline 1 & $34(28.3)$ \\
\hline 2 & $6(5.0)$ \\
\hline 3 & $1(0.8)$ \\
\hline$>4$ times & $1(0.8)$ \\
\hline Prior RT (no. [\%]) & $1(0.8)$ \\
\hline Prior hydrocephalus status post-VP shunt (no. [\%]) & $5(4.2)$ \\
\hline $\begin{array}{l}\text { Median period btwn symptoms \& GKRS in mos } \\
\text { (range) }\end{array}$ & $19(0-324)$ \\
\hline Median KPS score (range) & $90(0-100)$ \\
\hline Median RPA (range) & $1(0-4)$ \\
\hline \multicolumn{2}{|l|}{ GKRS parameters } \\
\hline Median radiation vol (range) & $3.6(0.3-23.9)$ \\
\hline Median margin dose in Gy (range) & $15(8-20)$ \\
\hline Median max dose in Gy (range) & $30(20-60)$ \\
\hline Mean isodose line in \% (range) & $50(30-60)$ \\
\hline Median conformal index (range) & $1.2(0.4-2.0)$ \\
\hline Median clinical FU in mos (range) & $79.5(15-224)$ \\
\hline Median imaging FU in mos (range) & $72(6-213)$ \\
\hline
\end{tabular}

$\mathrm{CN}=$ cranial nerve; $\mathrm{CPA}=$ cerebellopontine angle; $\mathrm{FU}=$ follow-up; $\mathrm{KPS}=$ Karnofsky Performance Status; RPA = recursive partitioning analysis; $R T$ = radiotherapy; VP = ventriculoperitoneal.

for each available imaging data set by using postcontrast T1-weighted imaging for the contouring. Computations were done through slice-by-slice area calculations of the meningioma and numerical integration with the trapezoid rule. ${ }^{25}$ For contouring and volume computations, ImageJ software was used.

\section{Statistical Analysis}

Statistical analysis was performed using a commercially available statistical package (IBM SPSS, version 20, IBM Corp.). Descriptive statistics were calculated for all variables, including the mean, median, standard deviation, and frequency distributions, as appropriate. Univariate logistic regression was used to evaluate clinical covariates hypothesized to predict tumor control and post-GKRS improvement, including age, tumor volume at the time of GKRS, sex, radiation dose, and period between symptoms and GKRS. Kaplan-Meier analysis was performed for tumor control and post-GKRS improvement. All statistical tests were 2-sided unless indicated otherwise. A p $<0.05$ was considered statistically significant. For the prediction of tumor volume changes, we attempted to correlate tumor volume changes (\%) at the 3-year post-SRS follow-up and at the 5- and 10-year post-SRS follow-up by using linear regression. The $\mathrm{R}^{2}$, coefficient of determination, was also computed.

\section{Results \\ Patient and Tumor Attributes}

The final study cohort included 120 patients. Patient attributes and tumor characteristics are outlined in Tables 1 and 2. The final cohort consisted of $76.6 \%$ (92) female patients, and the cohort median age was 61 years (12-88 years). The most common neurological symptoms before SRS were dizziness or imbalance (44 patients [36.6\%]), headache (44 patients [36.6\%]), auditory dysfunction (30 patients [25\%]), and facial numbness/hypesthesia (29 patients [24.2\%]). The most common tumor location was the cerebellopontine angle (38 lesions [31.7\%]), followed by the tentorium (28 [23.3\%]), clivus (24 [20\%]), petroclival region (23 [19.2\%]), and other locations (7 [5.8\%]). The median pre-SRS volume of the PFMs was $4.0 \mathrm{~cm}^{3}$ (range 0.4-40.9 $\mathrm{cm}^{3}$ ). The most common pre-SRS cranial nerve deficit was a trigeminal nerve deficit (47 patients [39.1\%]), followed by vestibular nerve deficit (44 [36.6\%]), cochlear nerve deficit (30 [25\%]), and facial nerve palsy (10 [8.3\%]). Stereotactic radiosurgery was the primary treatment for $65 \%$ of the patients (78), whereas $28.3 \%$ (34) had undergone only 1 resection before SRS, and 6.7\% (8) had undergone 2 or more resections prior to SRS. The median time from the development of associated neurological symptoms to treatment with SRS was 19 months (range 0-324 months).

\section{Tumor Control}

Specific parameters of tumor control are outlined in Table 3. The overall tumor control rate was $89.2 \%$ (107 patients), with a median clinical and imaging follow-up of 79.5 (15-224) and 72 (6-213) months, respectively. Eightysix patients $(71.7 \%)$ demonstrated tumor volume regression (volume decrease by $10 \%$ or more) and 21 (17.5\%) demonstrated tumor volume stability (change in volume < $10 \%)$. Tumor progression was noted in 13 patients $(10.8 \%)$ at the last follow-up. Tumor progression occurred as an infield recurrence in 9 patients $(7.5 \%)$ and as an outfield recurrence in 4 (3.3\%). Overall 2-, 4-, 6-, 8-, and 10-year actuarial progression-free survival (PFS) rates were $97.5 \%$, $94.4 \%, 89.5 \%, 85.8 \%$, and $85.8 \%$, respectively (Fig. 1). Adverse radiation effects were documented in 9 patients (7.5\%). We did not observe imaging features or histological confirmation of radionecrosis following resection in this series. 
TABLE 2. Neurological signs and CN deficits in 120 patients pre- and post-GKRS

\begin{tabular}{|c|c|c|c|c|}
\hline \multirow[b]{2}{*}{ Signs \& Deficits } & \multicolumn{2}{|c|}{ Before GKRS } & \multicolumn{2}{|c|}{ After GKRS } \\
\hline & Intact & Impaired & Non-Deterioration & Deterioration \\
\hline \multicolumn{5}{|l|}{ Neurological symptom } \\
\hline Headache & 76 & 44 & 114 & 4 \\
\hline Cerebellar sign including ataxia & 108 & 12 & 118 & 2 \\
\hline Cognition/orientation/memory & 108 & 12 & 120 & 0 \\
\hline \multicolumn{5}{|l|}{ Face sensation } \\
\hline Facial numbness/hypesthesia & 91 & 29 & 117 & 3 \\
\hline Facial pain & 104 & 16 & 119 & 1 \\
\hline Facial paresthesia & 118 & 2 & 119 & 1 \\
\hline Masseter weakness & 119 & 1 & 120 & 0 \\
\hline Facial weakness & 111 & 9 & 119 & 1 \\
\hline Facial spasm/twitch & 119 & 1 & 119 & 1 \\
\hline Auditory dysfunction & 90 & 30 & 118 & 2 \\
\hline Dizziness/imbalance & 76 & 44 & 120 & 0 \\
\hline Dysphagia & 119 & 1 & 119 & 1 \\
\hline \multicolumn{5}{|l|}{ Body sensation } \\
\hline Numbness/hypesthesia & 115 & 5 & 119 & 1 \\
\hline Pain & 119 & 1 & 120 & 0 \\
\hline Paresthesia/tingling & 118 & 2 & 120 & 0 \\
\hline Body weakness & 108 & 12 & 119 & 1 \\
\hline Impaired shoulder shrug & 119 & 1 & 120 & 0 \\
\hline Tongue deviation & 118 & 2 & 120 & 0 \\
\hline \multicolumn{5}{|l|}{$\mathrm{CN}$ deficit } \\
\hline Trigeminal nerve & 73 & 47 & 116 & 4 \\
\hline Abducens nerve & 120 & 0 & 120 & 0 \\
\hline Facial nerve & 110 & 10 & 119 & 1 \\
\hline Cochlear nerve & 90 & 30 & 118 & 2 \\
\hline Vestibular nerve & 76 & 44 & 120 & 0 \\
\hline Glossopharyngeal nerve & 119 & 1 & 119 & 1 \\
\hline Vagus nerve & 119 & 1 & 119 & 1 \\
\hline Accessory nerve & 119 & 1 & 120 & 0 \\
\hline Hypoglossal nerve & 118 & 2 & 120 & 0 \\
\hline
\end{tabular}

Overall post-GKRS neurological improvement: 23.3\% (28 patients) improved, $70.8 \%$ (85 patients) remained stable, and 5.8\% (7 patients) deteriorated.

\section{Clinical and Neurological Outcomes}

The most common post-SRS neurological symptoms were headache (4 patients [3.3\%]), followed by facial numbness/hypesthesia (3 patients [2.5\%]), cerebellar ataxia (2 patients [1.6\%]), auditory dysfunction (2 patients [1.6\%]), trigeminal neuralgia (1 patient [0.8\%]), facial weakness (1 patient [0.8\%]), facial spasm (1 patient $[0.8 \%])$, dysphagia (1 patient [0.8\%]), body numbness $(1$ patient $[0.8 \%]$ ), and hemiparesis (1 patient [0.8\%]; Table 2). Improvement in neurological function after SRS was observed in 28 patients (23.3\%), whereas symptoms remained stable in $85(70.8 \%)$ and deteriorated (new or worsened deficit) in 7 (5.8\%). We evaluated the impact of tumor progression on the development of new or worsening neurological deficits at the last follow-up from SRS, but the relation was not statistically significant $(\mathrm{p}=0.874$, logistic regression).

\section{Pre-SRS Factors Influencing Tumor Progression}

Cox regression was used to evaluate for any pre-SRS characteristics that predicted local failure. Through multivariate analysis, we found that a low margin dose is the only predictor of tumor progression $(\mathrm{p}=0.007$; Table 4$)$. For patients treated with a margin dose $\geq 16 \mathrm{~Gy}$, actuarial PFS rates were $100 \%$. For patients treated with a margin dose of 13-15 Gy, the actuarial PFS rates at 2, 4, 6, 8, and 10 years were $97.5 \%, 97.5 \%, 93.4 \%, 93.4 \%$, and $93.4 \%$, respectively. Those who were treated with $\leq 12$ Gy had actuarial PFS rates of $95.8 \%, 82.9 \%, 73.2 \%, 56.9 \%$, and $56.9 \%$ at 2, 4, 6, 8, and 10 years, respectively (Fig. 2).

\section{Early Volume Changes as a Predictor of Long-Term Response}

Volumetric analysis data are shown in Fig. 3. Tumor volume changes through the follow-up period for each 
TABLE 3. Outcome of GKRS treatments in patients with PFM

\begin{tabular}{cc}
\hline \multicolumn{1}{c}{ Parameter } & No. $(\%)$ \\
\hline Tumor response & \\
\hline Regression: vol decrease $\geq 10 \%$ & $86(71.7)$ \\
\hline Stable: vol change $<10 \%$ & $21(17.5)$ \\
\hline Progression: vol increase $>10 \%$ & $13(10.8)$ \\
\hline Infield recurrence & $9(7.5)$ \\
\hline Outfield recurrence & $4(3.3)$ \\
\hline Complication & \\
\hline None & $111(92.5)$ \\
\hline AREs & $9(7.5)$ \\
\hline Radiation necrosis & $0(0)$ \\
\hline Further intervention & $2(1.7)$ \\
\hline Resection & $2(1.7)$ \\
\hline Repeated GKRS & $1(0.8)$ \\
\hline For same tumor, infield recurrence & $1(0.8)$ \\
\hline For new tumor, outfield recurrence
\end{tabular}

$\mathrm{ARE}=$ adverse radiation effect.

patient are shown relative to the volume at the time of initial treatment, which was defined as $100 \%$. The linear regression model is also shown in Fig. 3. Tumor volume measurements at the early follow-up of 3 years after SRS appear predictive of the 5- and 10-year tumor volumetric response after SRS. Figures 4 and 5 show that tumor volume change at the early follow-up at 3 years predicts the long-term tumor volume change at 5 years with good reliability $\left(\mathrm{R}^{2}=0.756\right)$ with a $\mathrm{p}<0.001$ and at 10 years with less reliability $\left(\mathrm{R}^{2}=0.421\right)$ with a $\mathrm{p}=0.001$. We also determined that the 1- to 5-year tumor response is predictive of the 5- to 10 -year response $\left(\mathrm{R}^{2}=0.636, \mathrm{p}<0.001\right.$; Fig. 6$)$.

\section{Management of Tumor Progression}

There were a total of 13 tumor progressions either infield (9 patients) or outfield (4 patients). Of these patients, 4 underwent additional treatment including resection (2 patients [1.7\%]) or repeated radiosurgery (2 patients [1.7\%]; Table 5). Resection was performed for 2 patients who developed new focal neurological deficits (dysphagia, hemiparesis and facial weakness, spasms). The remaining 9 patients were followed conservatively. Those with progression (either infield or out of field) demonstrated the progression at times ranging from 52 to 84 months after SRS. The interval for progression in these cases emphasizes the need for long-term follow-up even in tumors that show an initially favorable response.

\section{Discussion}

Posterior fossa meningioma is a challenging clinical entity for neurosurgeons given its location along the skull base, which presents significant potential morbidities from the surgical approach. It is also challenging due to its frequent vascularity, firm consistency, and proximity to the brainstem, cranial nerves, and other critical neurovascular structures. ${ }^{1-10,12,14,18,24,27-29,32,35,39,51,54,55,57-59,64}$ In addition to the high rates of morbidity and mortality as-

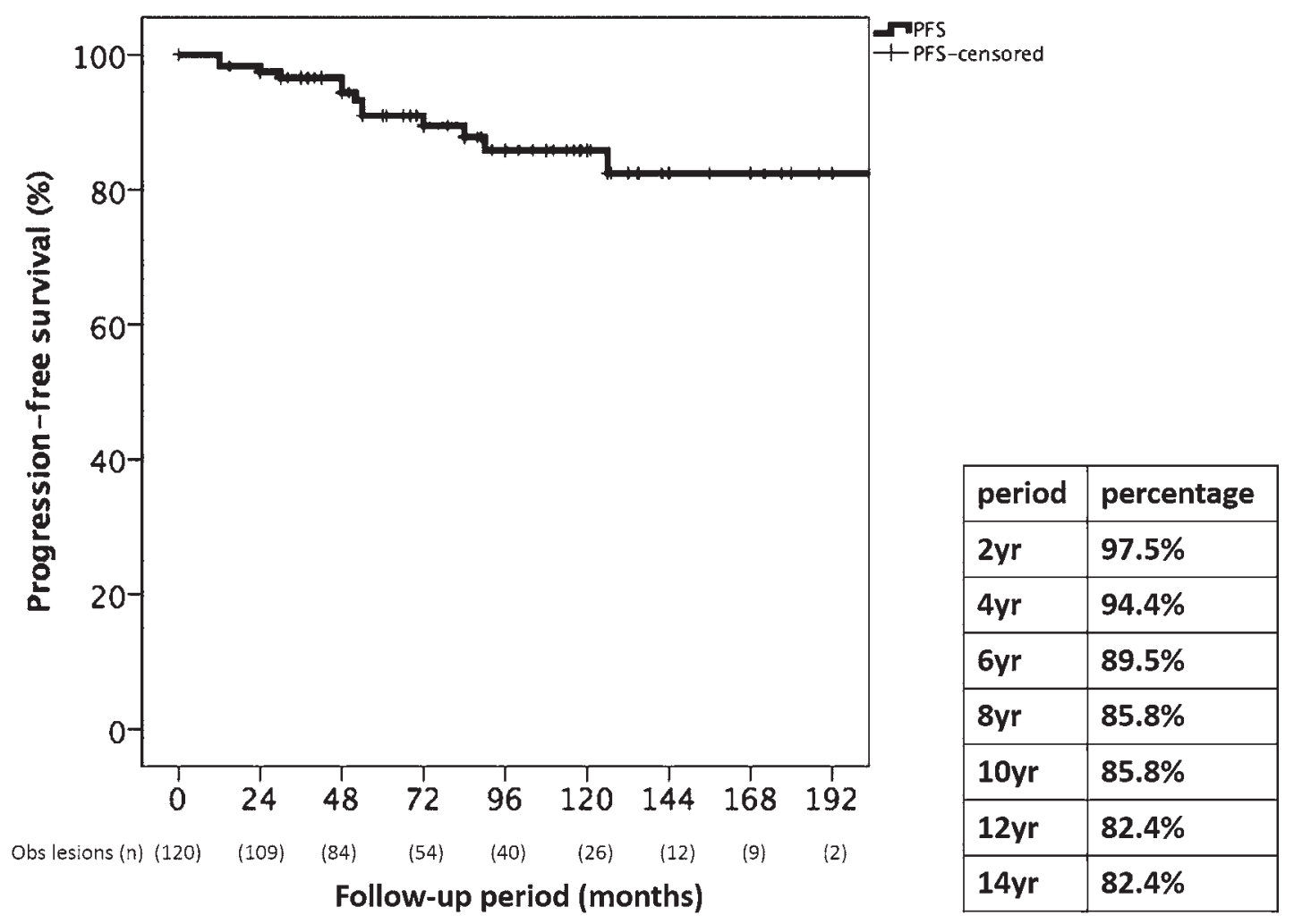

FIG. 1. Kaplan-Meier curve representing overall actuarial PFS. 
TABLE 4. Prognostic factors associated with local failure

\begin{tabular}{|c|c|c|c|c|c|c|c|}
\hline \multirow[b]{2}{*}{ Factor } & \multirow{2}{*}{$\begin{array}{c}\text { No. of } \\
\text { Patients }\end{array}$} & \multicolumn{3}{|c|}{ Univariate } & \multicolumn{3}{|c|}{ Multivariate } \\
\hline & & p Value & $\mathrm{HR}^{*}$ & $95 \% \mathrm{Cl}$ & $p$ Value & $\mathrm{HR}^{*}$ & $95 \% \mathrm{Cl}$ \\
\hline Age & & 0.296 & & & & & \\
\hline$\leq 65 \mathrm{yrs}$ & 78 & & Ref & & & & \\
\hline$>65$ yrs & 42 & & 0.446 & $0.098-2.027$ & & & \\
\hline Sex & & 0.452 & & & & & \\
\hline M & 28 & & Ref & & & & \\
\hline $\mathrm{F}$ & 92 & & 1.785 & $0.395-8.069$ & & & \\
\hline No. of tumors & & 0.111 & & & 0.067 & & \\
\hline Single & 111 & & Ref & & & Ref & \\
\hline Multiple & 9 & & 3.422 & $0.753-15.554$ & & 4.355 & $0.904-20.966$ \\
\hline Previous op & & 0.410 & & & & & \\
\hline Yes & 78 & & Ref & & & & \\
\hline No & 42 & & 0.608 & $0.186-1.985$ & & & \\
\hline Lesion location & & 0.907 & & & & & \\
\hline Tentorium & 28 & 0.650 & 1.769 & $0.150-20.815$ & & & \\
\hline CPA & 38 & 1.000 & 0.000 & $0.000-0.000$ & & & \\
\hline Petroclival & 23 & 0.269 & 3.485 & $0.382-31.832$ & & & \\
\hline Petrous & 2 & 0.975 & 1.045 & $0.062-17.765$ & & & \\
\hline Foramen magnum & 4 & 0.999 & 0.000 & $0.000-0.000$ & & & \\
\hline Clivus & 24 & 0.999 & 0.000 & $0.000-0.000$ & & & \\
\hline Tentorium \& CPA & 1 & 0.999 & 0.000 & $0.000-0.000$ & & & \\
\hline Tumor vol at GKRS & & 0.988 & & & & & \\
\hline$<4 \mathrm{~cm}^{3}$ & 60 & & Ref & & & & \\
\hline $4-10 \mathrm{~cm}^{3}$ & 43 & 0.880 & 0.919 & $0.971-2.961$ & & & \\
\hline$>10 \mathrm{~cm}^{3}$ & 17 & 0.977 & 0.000 & 0.000 & & & \\
\hline Margin dose & & 0.011 & & & 0.007 & & \\
\hline$\leq 12 \mathrm{~Gy}$ & 24 & & Ref & & & Ref & \\
\hline 13-15 Gy & 80 & 0.003 & 0.179 & $0.058-0.553$ & 0.002 & 0.159 & $0.050-0.501$ \\
\hline$\geq 16$ Gy & 16 & 0.977 & 0.000 & 0.000 & 0.978 & 0.000 & 0.000 \\
\hline Max dose & & 0.364 & & & & & \\
\hline$\leq 30$ Gy & 68 & & Ref & & & & \\
\hline 31-39 Gy & 30 & 0.398 & 1.640 & $0.520-5.170$ & & & \\
\hline$\geq 40 \mathrm{~Gy}$ & 22 & 0.356 & 0.373 & $0.046-3.035$ & & & \\
\hline Period btwn symptoms \& GKRS & 120 & 0.943 & 1.000 & $0.990-1.009$ & & & \\
\hline
\end{tabular}

sociated with resection, delayed recurrence after partial or even complete resection has been noted and suggests the need for other management techniques for these unique lesions. ${ }^{1-10,12,14,18,24,27-29,32,35,39,51,54,55,57-59,64}$ Rates of complete resection for PFMs vary considerably, ranging from $40 \%$ to $96 \%$, and recurrence rates after upfront resection range from $12 \%$ to $91 \%$. $12,4-10,12,14,18,24,27-29,32,35,39,51,54,61$ Furthermore, resection planes during repeat resections pose added difficulty associated with increased morbidity and mortality. ${ }^{6,729,71}$ Resection remains valuable for patients with appreciable mass effect from a tumor or when tissue diagnosis is required. Regarding the extent of resection, many have recently proposed conservative subtotal resection prioritizing the relief of mass effect and avoiding neurological injury, while others had previously supported aggressive resection. Even with conservative resection tactics, however, recent studies in patients undergoing resection of PFMs have still reported morbidity and mortality rates of $13 \%-40 \%$ and $0 \%-13 \%$, respectively. ${ }^{8,43,71}$

\section{Radiosurgery for PFMs}

Meningiomas are increasingly found at earlier stages because of the increased accessibility and cost-utility of radiological imaging. Consequently, they are increasingly asymptomatic or associated with minimal symptoms. The meningioma control rates reported following SRS have been high. $2,10,11,13,15,17,19-21,26,30,31,34,40,41,44-50,52,53,56,61$, 65-67,70,71 Progression-free survival rates greater than 90\% have been reported for adjuvant SRS (postresection) at a minimum 5-year follow-up. 11,23,25,38,42,45,61,65 Similar rates 


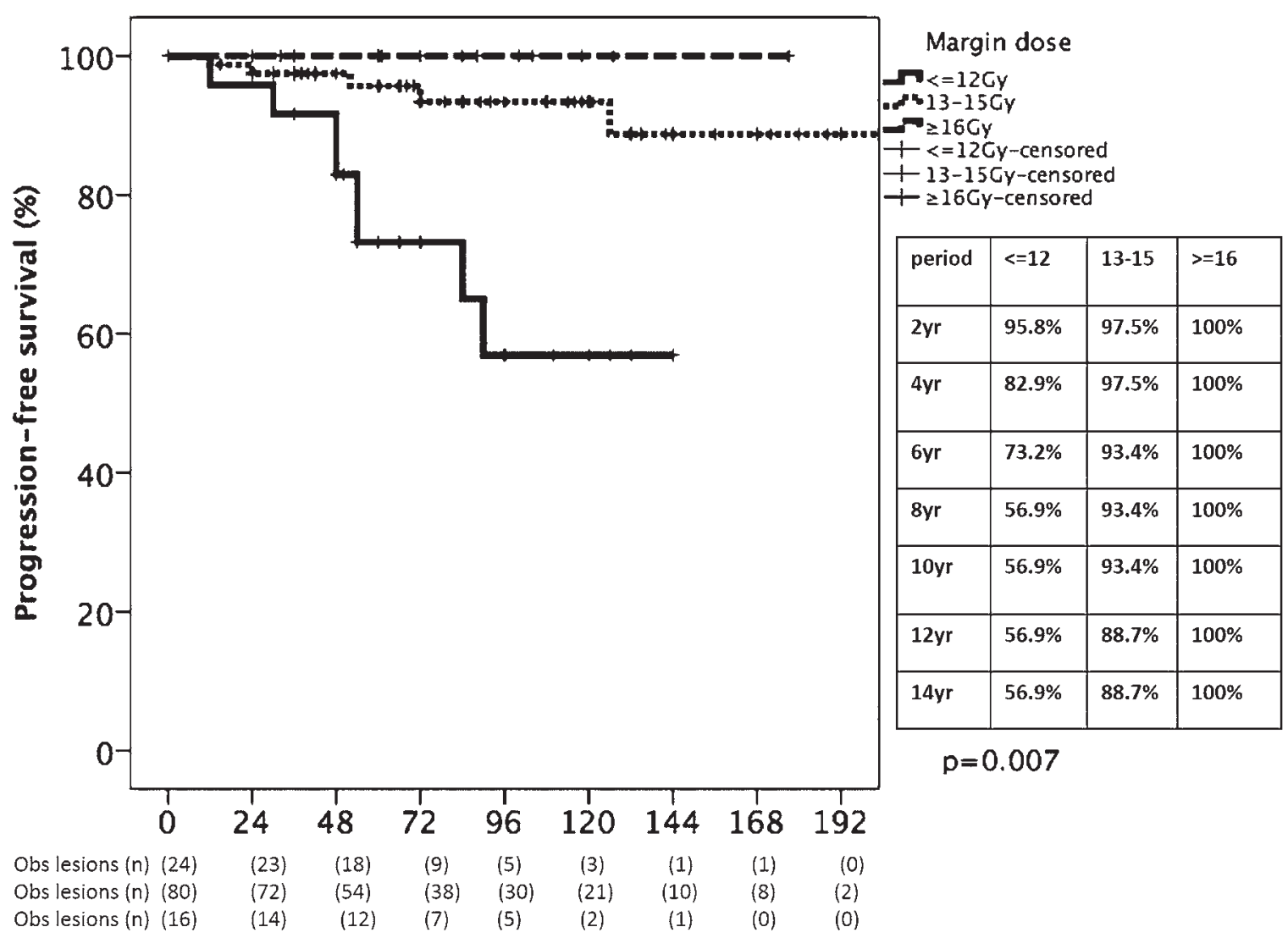

\section{Follow-up period (months)}

FIG. 2. Kaplan-Meier curve representing tumor margin dose-based actuarial PFS. Obs = observed.

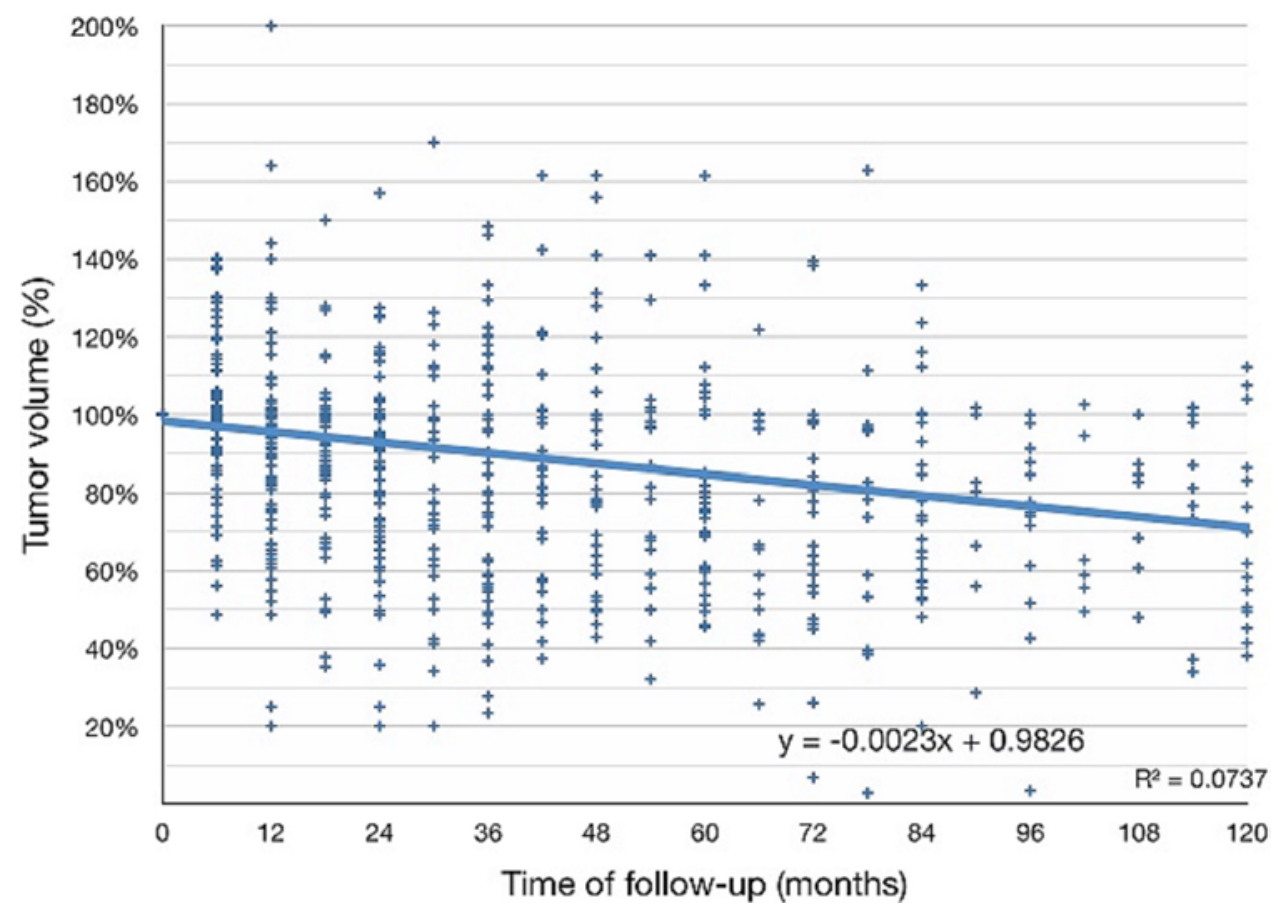

FIG. 3. Individual patients' volumetric data indicating changes (\%) in tumor volume during the follow-up period. The change is depicted as a line by using linear regression $\left(R^{2}=0.0737, y=-0.0023 x+0.9826\right)$, showing overall tumor control. Figure is available in color online only. 


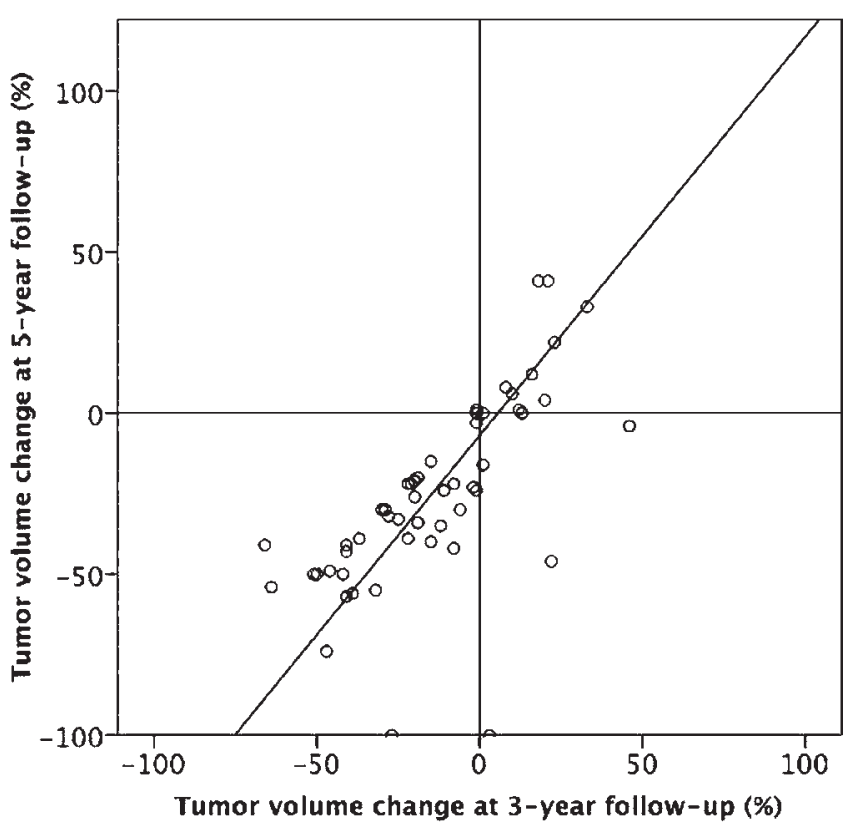

FIG. 4. The correlation between tumor volume changes (\%) at the 3 -year post-SRS follow-up and at the 5-year post-SRS follow-up. A strong linear correlation is shown $\left(R^{2}=0.756\right)$

have also been reported after SRS as the primary treatment. ${ }^{11,23,36-38,42,45,61,65}$

Table 6 outlines radiosurgical studies in the literature that specifically focused on PFMs. ${ }^{26,45,53,61,65-67,72}$ The follow-up period among these studies ranges from 28.7 to 84 months. Additional characteristics include overall tumor control rates from $87 \%$ to $100 \%$, rates of preserved neurological function from $85 \%$ to $100 \%$, and complication rates from $0 \%$ to $9 \%$. Prognostic factors for tumor advancement included age greater than 65 years, prior history of radiotherapy, and increasing tumor volume. ${ }^{26,53,61,65-67}$ In the current study, we found that a margin dose $<16$ Gy portended a lower chance of long-term volumetric control. In the literature, factors predictive of neurological deterioration after SRS included increasing tumor volume and a tumor location in the clivus, petrous portion, or cerebellopontine angle (as opposed to the foramen magnum, tentorium, or petroclival region), ${ }^{26,53,61,65-67}$ but these factors did not show any statistically significant relation in the present study, probably secondary to the lower number of complications.

We did not find a statistically significant factor that predicted neurological decline in our patient cohort with PFMs. In particular, we did not find a significant association between tumor progression and neurological decline ( $\mathrm{p}=0.874$, OR $1.121,95 \% \mathrm{CI} 0.875-1.682)$. This is proba-

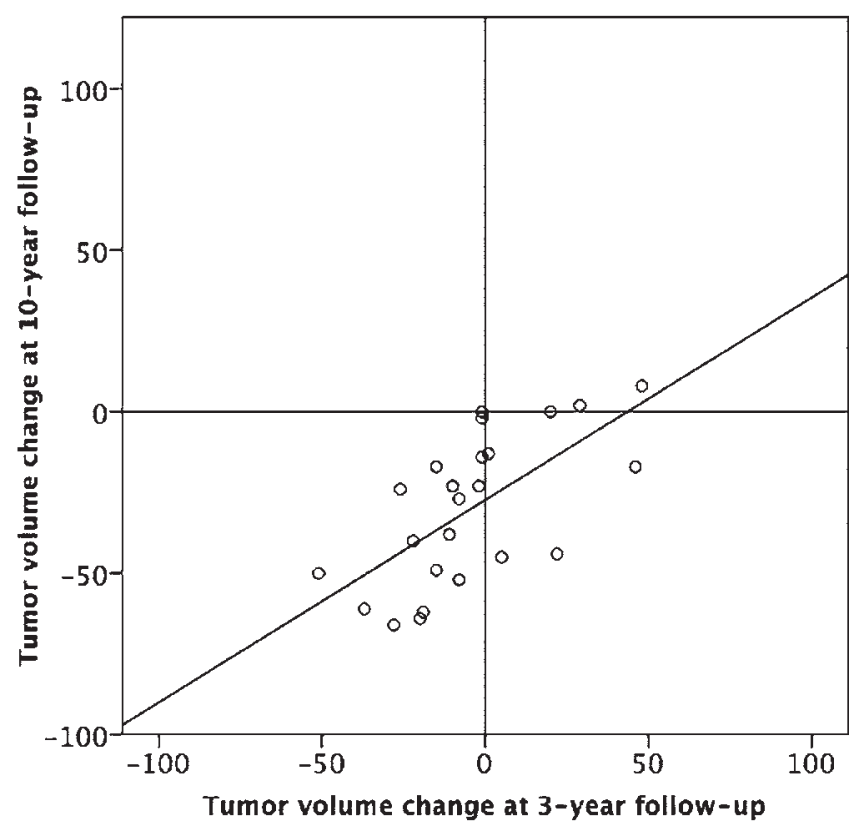

FIG. 5. The correlation between tumor volume changes (\%) at the 3 -year post-SRS follow-up and at the 10-year post-SRS follow-up. A moderate linear correlation is shown $\left(R^{2}=0.421\right)$.

bly attributable to the modest statistical power and low incidence of neurological deficits following radiosurgery in our series. However, in a larger multicenter study of SRS for PFMs including 675 patients, tumor progression was a significant predictor of neurological decline after SRS. ${ }^{61}$ However, this finding may have been an artifact of selection bias and the fact that most of the patients in that study demonstrated either neurological improvement or stability at the last follow-up.

Our results largely substantiate those from other studies with a similar follow-up (median clinical follow-up of 79.5 months and radiological follow-up of 72 months) and uniquely demonstrate predictability with tumor volumetric change. Importantly, the tumor volumetric change at the short-term follow-up of 3 years reliably predicted the long-term follow-up at 5 years and reasonably predicted the long-term follow-up at 10 years. We noted higher tumor control rates when PFMs were treated with a margin dose $\geq 16$ Gy. Therefore, a favorable volumetric response at 3 years serves as an early predictor of a durable and probably successful response for the long-term radiological outcome (Figs. 4 and 5).

\section{Study Limitations}

This study is inherently limited by its retrospective data

TABLE 5. Management when patients had PFM enlargement

\begin{tabular}{ccccc}
\hline Second Treatment & TV at GKRS $\left(\mathrm{cm}^{3}\right)$ & TV at Recurrence $\left(\mathrm{cm}^{3}\right)$ & Increment $(\%)$ & Interval (mos) \\
\hline Craniotomy $(\mathrm{n}=2)$ & $1.0,17.0$ & $5.0,30.2$ & $500 \%, 178 \%$ & 52,72 \\
\hline Repeated GKRS $(\mathrm{n}=2)$ & $3.9,8.4$ & $5.4,11.8$ & $139 \%, 141 \%$ & 54,84 \\
\hline
\end{tabular}

Interval = time interval between GKRS and the observation of recurrence; TV = tumor volume.

Data are presented as case 1, case 2. 


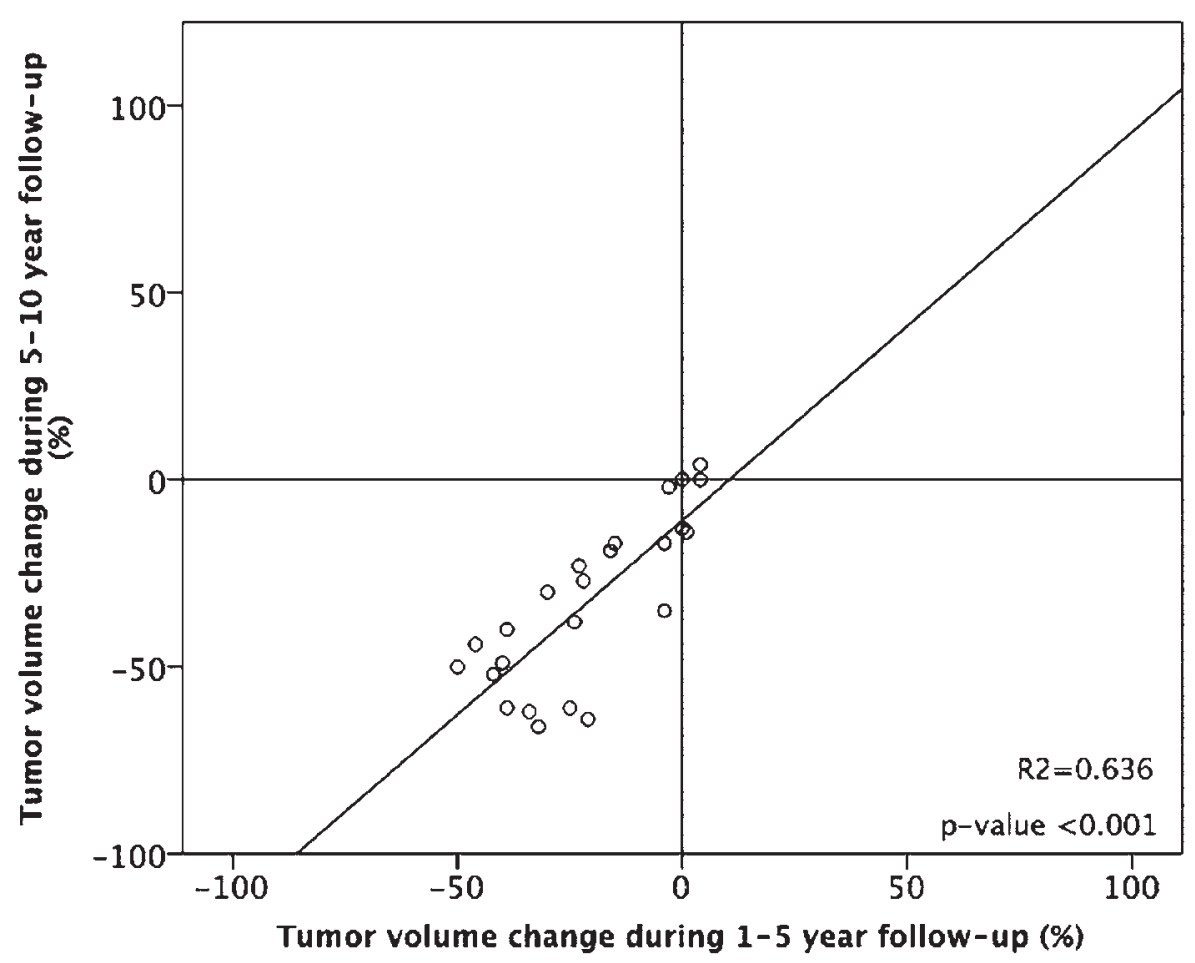

FIG. 6. The correlation between tumor volume changes $(\%)$ at the 1 - to 5 -year post-SRS follow-up and at the 5 - to 10 -year postSRS follow-up. A strong linear correlation is shown $\left(R^{2}=0.636\right)$

collection and analysis. Patients who underwent SRS as a primary treatment had a presumed diagnosis of a benign WHO grade I meningioma but lacked a definitive histological diagnosis. The posterior fossa contains numerous sublocations, and meningiomas within each specific location can reasonably differ with respect to behavior, natural history, and SRS response. Selection bias may have affected the use of upfront radiosurgery, resection, radiation therapy, and salvage radiosurgery. Further limitations include those inherent to a single-center study. There may be patient selection bias within the treatment algorithms of our center. Patients who developed complications postSRS may be overrepresented as it is likely that they were followed up more frequently and with more evaluations. While the considerable long-term follow-up is a strength of our study, the extensive period of time over which SRS was performed includes changes in the Gamma Knife unit, the Gamma Knife software, and imaging. Lastly, the results of this single-center analysis may not be completely generalizable and reflect data from a tertiary care center with appreciable experience with SRS.

\section{Conclusions}

Stereotactic radiosurgery, as an either upfront or adjuvant treatment, is a durable therapeutic option in appropriate candidates with benign PFMs, with high rates of tumor control and suitably low incidences of post-SRS neurological deficits compared with those following alternate treatment modalities. Doses of 13-16 Gy seem to afford reasonable tumor control and neurological preservation for the majority of PFM patients. Lesion volumetric response at the short-term follow-up of 3 years is predictive of the long-term response at 5 and 10 years.

TABLE 6. Literature review of major radiosurgical studies on PFMs

\begin{tabular}{lcccccc}
\hline \multicolumn{1}{c}{ Authors \& Year } & No. of Cases & FU (median/mean) & \% Tumor Control & Volumetry & \% Neurological Preservation & \% Neurological Complications \\
\hline Subach et al., 1998 & 62 & 37 & 92 & No & 87 & 8 \\
\hline Nicolato et al., 2001 & 57 & 28.7 & 95 & No & 100 & 6.5 \\
\hline Flannery et al., 2010 & 168 & 72 & 90 & No & 85 & 8 \\
\hline Starke et al., 2011 & 152 & 84 & 87 & No & 91 & 9 \\
\hline Zenonos et al., 2012 & 24 & 47 & 100 & No & 100 & 0 \\
\hline Sheehan et al, 2015 & 675 & 60 & 91 & No & 92.3 & 7.7 \\
\hline Current study & 120 & 79.5 & 89.2 & Yes & 94.2 & 5.8 \\
\hline
\end{tabular}




\section{References}

1. Adegbite AB, Khan MI, Paine KW, Tan LK: The recurrence of intracranial meningiomas after surgical treatment. J Neurosurg 58:51-56, 1983

2. Aichholzer M, Bertalanffy A, Dietrich W, Roessler K, Pfisterer W, Ungersboeck K, et al: Gamma Knife radiosurgery of skull base meningiomas. Acta Neurochir (Wien) 142:647653,2000

3. Al-Mefty O: Clinoidal meningiomas. J Neurosurg 73:840849,1990

4. Al-Mefty O, Fox JL, Smith RR: Petrosal approach for petroclival meningiomas. Neurosurgery 22:510-517, 1988

5. Arnautović KI, Al-Mefty O: Primary meningiomas of the jugular fossa. J Neurosurg 97:12-20, 2002

6. Arnautović KI, Al-Mefty O, Husain M: Ventral foramen magnum meninigiomas. J Neurosurg 92 (1 Suppl):71-80, 2000

7. Babu RP, Sekhar LN, Wright DC: Extreme lateral transcondylar approach: technical improvements and lessons learned. J Neurosurg 81:49-59, 1994

8. Bassiouni H, Ntoukas V, Asgari S, Sandalcioglu EI, Stolke D, Seifert V: Foramen magnum meningiomas: clinical outcome after microsurgical resection via a posterolateral suboccipital retrocondylar approach. Neurosurgery 59:1177-1187, 2006

9. Bertalanffy H, Gilsbach JM, Mayfrank L, Klein HM, Kawase T, Seeger W: Microsurgical management of ventral and ventrolateral foramen magnum meningiomas. Acta Neurochir Suppl 65:82-85, 1996

10. Black PM, Villavicencio AT, Rhouddou C, Loeffler JS: Aggressive surgery and focal radiation in the management of meningiomas of the skull base: preservation of function with maintenance of local control. Acta Neurochir (Wien) 143:555-562, 2001

11. Bloch O, Kaur G, Jian BJ, Parsa AT, Barani IJ: Stereotactic radiosurgery for benign meningiomas. J Neurooncol 107:13-20, 2012

12. Bruneau M, George B: Foramen magnum meningiomas: detailed surgical approaches and technical aspects at Lariboisière Hospital and review of the literature. Neurosurg Rev 31:19-33, 2008

13. Chang SD, Adler JR Jr: Treatment of cranial base meningiomas with linear accelerator radiosurgery. Neurosurgery 41:1019-1027, 1997

14. Cho CW, Al-Mefty O: Combined petrosal approach to petroclival meningiomas. Neurosurgery 51:708-718, 2002

15. Chuang CC, Chang CN, Tsang NM, Wei KC, Tseng CK, Chang JT, et al: Linear accelerator-based radiosurgery in the management of skull base meningiomas. J Neurooncol 66:241-249, 2004

16. Cohen-Inbar O, Lee CC, Sheehan JP: The contemporary role of stereotactic radiosurgery in the treatment of meningiomas. Neurosurg Clin N Am 27:215-228, 2016

17. Couldwell WT, Cole CD, Al-Mefty O: Patterns of skull base meningioma progression after failed radiosurgery. J Neurosurg 106:30-35, 2007

18. Cudlip SA, Wilkins PR, Johnston FG, Moore AJ, Marsh HT, Bell BA: Posterior fossa meningiomas: surgical experience in 52 cases. Acta Neurochir (Wien) 140:1007-1012, 1998

19. De Salles AA, Frighetto L, Grande CV, Solberg TD, Cabatan-Awang C, Selch MT, et al: Radiosurgery and stereotactic radiation therapy of skull base meningiomas: proposal of a grading system. Stereotact Funct Neurosurg 76:218-229, 2001

20. Debus J, Wuendrich M, Pirzkall A, Hoess A, Schlegel W, Zuna I, et al: High efficacy of fractionated stereotactic radiotherapy of large base-of-skull meningiomas: long-term results. J Clin Oncol 19:3547-3553, 2001

21. Deinsberger R, Tidstrand J, Sabitzer H, Lanner G: LINAC radiosurgery in skull base meningiomas. Minim Invasive Neurosurg 47:333-338, 2004
22. Deltour I, Johansen C, Auvinen A, Feychting M, Klaeboe L, Schüz J: Time trends in brain tumor incidence rates in Denmark, Finland, Norway, and Sweden, 1974-2003. J Natl Cancer Inst 101:1721-1724, 2009

23. dos Santos MA, de Salcedo JB, Gutiérrez Diaz JA, Calvo FA, Samblás J, Marsiglia H, et al: Long-term outcomes of stereotactic radiosurgery for treatment of cavernous sinus meningiomas. Int J Radiat Oncol Biol Phys 81:1436-1441, 2011

24. Erkmen K, Pravdenkova S, Al-Mefty O: Surgical management of petroclival meningiomas: factors determining the choice of approach. Neurosurg Focus 19(2):E7, 2005

25. Feigl GC, Samii M, Horstmann GA: Volumetric follow-up of meningiomas: a quantitative method to evaluate treatment outcome of gamma knife radiosurgery. Neurosurgery 61:281-287, 2007

26. Flannery TJ, Kano H, Lunsford LD, Sirin S, Tormenti M, Niranjan A, et al: Long-term control of petroclival meningiomas through radiosurgery. J Neurosurg 112:957-964, 2010

27. George B, Dematons C, Cophignon J: Lateral approach to the anterior portion of the foramen magnum. Application to surgical removal of 14 benign tumors: technical note. Surg Neurol 29:484-490, 1988

28. George B, Lot G, Boissonnet H: Meningioma of the foramen magnum: a series of 40 cases. Surg Neurol 47:371-379, 1997

29. Goel A, Desai K, Muzumdar D: Surgery on anterior foramen magnum meningiomas using a conventional posterior suboccipital approach: a report on an experience with 17 cases. Neurosurgery 49:102-107, 2001

30. Hamm K, Henzel M, Gross MW, Surber G, Kleinert G, Engenhart-Cabillic R: Radiosurgery/stereotactic radiotherapy in the therapeutical concept for skull base meningiomas. Zentralbl Neurochir 69:14-21, 2008

31. Han JH, Kim DG, Chung HT, Park CK, Paek SH, Kim CY, et al: Gamma Knife radiosurgery for skull base meningiomas: long-term radiologic and clinical outcome. Int J Radiat Oncol Biol Phys 72:1324-1332, 2008

32. Harrison MJ, al-Mefty O: Tentorial meningiomas. Clin Neurosurg 44:451-466, 1997

33. Henzel M, Gross MW, Hamm K, Surber G, Kleinert G, Failing T, et al: Significant tumor volume reduction of meningiomas after stereotactic radiotherapy: results of a prospective multicenter study. Neurosurgery 59:1188-1194, 2006

34. Iwai Y, Yamanaka K, Ikeda H: Gamma Knife radiosurgery for skull base meningioma: long-term results of low-dose treatment. J Neurosurg 109:804-810, 2008

35. Kandenwein JA, Richter HP, Antoniadis G: Foramen magnum meningiomas-experience with the posterior suboccipital approach. Br J Neurosurg 23:33-39, 2009

36. Kimball MM, Friedman WA, Foote KD, Bova FJ, Chi YY: Linear accelerator radiosurgery for cavernous sinus meningiomas. Stereotact Funct Neurosurg 87:120-127, 2009

37. Kollová A, Liscák R, Novotný J Jr, Vladyka V, Simonová G, Janousková L: Gamma Knife surgery for benign meningioma. J Neurosurg 107:325-336, 2007

38. Kondziolka D, Flickinger JC, Dade Lunsford L: Clinical research in stereotactic radiosurgery: lessons learned from over 10,000 cases. Neurol Res 33:792-802, 2011

39. Kratimenos GP, Crockard HA: The far lateral approach for ventrally placed foramen magnum and upper cervical spine tumours. Br J Neurosurg 7:129-140, 1993

40. Kreil W, Luggin J, Fuchs I, Weigl V, Eustacchio S, Papaefthymiou G: Long term experience of gamma knife radiosurgery for benign skull base meningiomas. J Neurol Neurosurg Psychiatry 76:1425-1430, 2005

41. Liscák R, Kollová A, Vladyka V, Simonová G, Novotný J Jr: Gamma knife radiosurgery of skull base meningiomas. Acta Neurochir Suppl 91:65-74, 2004

42. Marta GN, Correa SF, Teixeira MJ: Meningioma: review of 
the literature with emphasis on the approach to radiotherapy. Expert Rev Anticancer Ther 11:1749-1758, 2011

43. Massager N, Murata N, Tamura M, Devriendt D, Levivier M, Régis J: Influence of nerve radiation dose in the incidence of trigeminal dysfunction after trigeminal neuralgia radiosurgery. Neurosurgery 60:681-688, 2007

44. McGregor JM, Sarkar A: Stereotactic radiosurgery and stereotactic radiotherapy in the treatment of skull base meningiomas. Otolaryngol Clin North Am 42:677-688, 2009

45. Mehta GU, Zenonos G, Patibandla MR, Lin CJ, Wolf A, Grills I, et al: Outcomes of stereotactic radiosurgery for foramen magnum meningiomas: an international multicenter study. J Neurosurg [epub ahead of print September 1, 2017. DOI: 10.3171/2017.3.JNS163008]

46. Milker-Zabel S, Zabel-du Bois A, Huber P, Schlegel W, Debus J: Intensity-modulated radiotherapy for complex-shaped meningioma of the skull base: long-term experience of a single institution. Int J Radiat Oncol Biol Phys 68:858-863, 2007

47. Morita A, Coffey RJ, Foote RL, Schiff D, Gorman D: Risk of injury to cranial nerves after Gamma Knife radiosurgery for skull base meningiomas: experience in 88 patients. J Neurosurg 90:42-49, 1999

48. Muthukumar N, Kondziolka D, Lunsford LD, Flickinger JC: Stereotactic radiosurgery for anterior foramen magnum meningiomas. Surg Neurol 51:268-273, 1999

49. Muthukumar N, Kondziolka D, Lunsford LD, Flickinger JC: Stereotactic radiosurgery for tentorial meningiomas. Acta Neurochir (Wien) 140:315-321, 1998

50. Nanda A, Vannemreddy P: Recurrence and outcome in skull base meningiomas: do they differ from other intracranial meningiomas? Skull Base 18:243-252, 2008

51. Nanda A, Vincent DA, Vannemreddy PS, Baskaya MK, Chanda A: Far-lateral approach to intradural lesions of the foramen magnum without resection of the occipital condyle. J Neurosurg 96:302-309, 2002

52. Nicolato A, Ferraresi P, Foroni R, Pasqualin A, Piovan E, Severi F, et al: Gamma Knife radiosurgery in skull base meningiomas. Preliminary experience with 50 cases. Stereotact Funct Neurosurg 66 (1 Suppl 1):112-120, 1996

53. Nicolato A, Foroni R, Pellegrino M, Ferraresi P, Alessandrini F, Gerosa M, et al: Gamma Knife radiosurgery in meningiomas of the posterior fossa. Experience with 62 treated lesions. Minim Invasive Neurosurg 44:211-217, 2001

54. Pamir MN, Kiliç T, Ozduman K, Türe U: Experience of a single institution treating foramen magnum meningiomas. J Clin Neurosci 11:863-867, 2004

55. Parlato C, Tessitore E, Schonauer C, Moraci A: Management of benign craniovertebral junction tumors. Acta Neurochir (Wien) 145:31-36, 2003

56. Pollock BE, Stafford SL, Utter A, Giannini C, Schreiner SA: Stereotactic radiosurgery provides equivalent tumor control to Simpson Grade 1 resection for patients with small- to medium-size meningiomas. Int J Radiat Oncol Biol Phys 55:1000-1005, 2003

57. Roberti F, Sekhar LN, Kalavakonda C, Wright DC: Posterior fossa meningiomas: surgical experience in 161 cases. Surg Neurol 56:8-21, 2001

58. Salas E, Sekhar LN, Ziyal IM, Caputy AJ, Wright DC: Variations of the extreme-lateral craniocervical approach: anatomical study and clinical analysis of 69 patients. J Neurosurg 90 (2 Suppl):206-219, 1999

59. Samii M, Klekamp J, Carvalho G: Surgical results for meningiomas of the craniocervical junction. Neurosurgery 39:1086-1095, 1996

60. Sekhar LN, Swamy NK, Jaiswal V, Rubinstein E, Hirsch WE Jr, Wright DC: Surgical excision of meningiomas involving the clivus: preoperative and intraoperative features as predic- tors of postoperative functional deterioration. J Neurosurg 81:860-868, 1994

61. Sheehan JP Sr, Starke RM, Kano H, Barnett GH, Mathieu $\mathrm{D}$, Chiang V, et al: Gamma Knife radiosurgery for posterior fossa meningiomas: a multicenter study. J Neurosurg 122:1479-1489, 2015

62. Simpson D: The recurrence of intracranial meningiomas after surgical treatment. J Neurol Neurosurg Psychiatry 20:22-39, 1957

63. Snell JW, Sheehan J, Stroila M, Steiner L: Assessment of imaging studies used with radiosurgery: a volumetric algorithm and an estimation of its error. Technical note. J Neurosurg 104:157-162, 2006

64. Stafford SL, Perry A, Suman VJ, Meyer FB, Scheithauer BW, Lohse CM, et al: Primarily resected meningiomas: outcome and prognostic factors in 581 Mayo Clinic patients, 1978 through 1988. Mayo Clin Proc 73:936-942, 1998

65. Starke RM, Nguyen JH, Rainey J, Williams BJ, Sherman JH, Savage J, et al: Gamma Knife surgery of meningiomas located in the posterior fossa: factors predictive of outcome and remission. J Neurosurg 114:1399-1409, 2011

66. Starke RM, Nguyen JH, Reames DL, Rainey J, Sheehan JP: Gamma Knife radiosurgery of meningiomas involving the foramen magnum. J Craniovertebr Junction Spine 1:23-28, 2010

67. Subach BR, Lunsford LD, Kondziolka D, Maitz AH, Flickinger JC: Management of petroclival meningiomas by stereotactic radiosurgery. Neurosurgery 42:437-445, 1998

68. Surawicz TS, McCarthy BJ, Kupelian V, Jukich PJ, Bruner JM, Davis FG: Descriptive epidemiology of primary brain and CNS tumors: results from the Central Brain Tumor Registry of the United States, 1990-1994. Neuro Oncol 1:14-25, 1999

69. Symon L, Pell M, Singh L: Surgical management of posterior cranial fossa meningiomas. Br J Neurosurg 7:599-609, 1993

70. Takanashi M, Fukuoka S, Hojyo A, Sasaki T, Nakagawara J, Nakamura H: Gamma knife radiosurgery for skull-base meningiomas. Prog Neurol Surg 22:96-111, 2009

71. Zachenhofer I, Wolfsberger S, Aichholzer M, Bertalanffy A, Roessler K, Kitz K, et al: Gamma-Knife radiosurgery for cranial base meningiomas: experience of tumor control, clinical course, and morbidity in a follow-up of more than 8 years. Neurosurgery 58:28-36, 2006

72. Zenonos G, Kondziolka D, Flickinger JC, Gardner P, Lunsford LD: Gamma Knife surgery in the treatment paradigm for foramen magnum meningiomas. J Neurosurg 117:864873,2012

\section{Disclosures}

The authors report no conflict of interest concerning the materials or methods used in this study or the findings specified in this paper.

\section{Author Contributions}

Conception and design: Sheehan, Patibandla. Acquisition of data: Patibandla, Addagada. Analysis and interpretation of data: Sheehan, Patibandla, Lee. Drafting the article: Sheehan, Patibandla, Tata, Addagada. Critically revising the article: Sheehan, Patibandla. Reviewed submitted version of manuscript: all authors. Approved the final version of the manuscript on behalf of all authors: Sheehan. Statistical analysis: Lee. Administrative/techni$\mathrm{cal} /$ material support: Sheehan. Study supervision: Sheehan.

\section{Correspondence}

Jason P. Sheehan: University of Virginia Health Sciences Center, Charlottesville, VA.jsheehan@virginia.edu. 